Collection: Cost Action E29 Meeting 2008 - Istanbul (Turkey)

Future Monitoring and Research Needs for Forest Ecosystems

Guest Editor: Marcus Schaub (WSL, Birmensdorf, CH)

\title{
An approach to measuring biodiversity and its use in analysing the effect of nitrogen deposition on woodland butterfly populations in the Netherlands
}

\begin{abstract}
Feest $A^{(1-2)}$, Spanos $K^{(3)}$
The current use of the term biodiversity is problematic in that it is frequently reduced to a paradigm of species richness through the interpretation of the CBD definition that identifies variability as the operative factor. Species richness actually conveys the least amount of information of all of the possible indices that could be used so a data treatment process has been established whereby taxonomic groups that have been sampled in a well-structured way can yield data that can be far more informative. An example using "biodiversity quality" indices for macrofungi following entry into a bespoke computer programme (FUNGIB) shows that these data can be established and they are capable of being assessed for statistical difference either between sites or over time. A case study showing how this approach can provide information on the mechanism whereby nitrogen deposition affects butterflies is given. It is clear that this approach can be of considerable use in establishing progress towards achieving the 2010 target of reducing the rate of loss of biodiversity by 2010 established by the CBD.
\end{abstract}

Keywords: Biodiversity quality, Butterflies, Macrofungi, Nitrogen critical load

\section{Introduction}

The definition of biodiversity given by the Convention on Biological Diversity 1992 (CBD) is as follows: "Biological diversity means the variability (our emphasis) among living organisms from all sources including inter alia, terrestrial, marine and other aquatic ecosystems and the ecological complexes of which they are part; this includes diversity within species, between species and of eco-

(1) Water and Environmental Management Research Centre, Department of Civil Engineering, Queen's Building, University of Bristol, Bristol BS8 1TR, UK; (2) Ecosulis Ltd, The Rickyard Newton St Loe, Bath BA2 9BT, UK; (3) NAGREF-FRI, GR-570 06, Vassilika, Greece

\section{@, Alan Feest (A.Feest@bristol.ac.uk)}

Received: Mar 29, 2008 - Accepted: Dec 9, 2008

Citation: Feest A, Spanos K, 2009. An approach to measuring biodiversity and its use in analysing the effect of nitrogen deposition on woodland butterfly populations in the Netherlands. iForest 2: 46-48 [online: 2009-01-29] URL:

http://www.sisef.it/iforest/show.php? id $=487$ systems".

It is clear that this definition was one arrived at after much negotiation and as such represents a compromise in positions. For those researchers working on biodiversity the definition does not work well as the operative word is "variability" and this word is undefined. Consequently biodiversity has come to mean whatever the researcher considered to be variability. The easiest and most frequently used interpretation is to equate biodiversity with Species Richness (the number of species in a unit area/sample), e.g., Billeter et al. 2008, Maiorano et al. 2007. This is patently not true as under this interpretation all species have the same properties and values.

We have developed a different approach to this problem by considering biodiversity to be a multi-faceted quality described by numerical indices that represent each of these facets. In this way the character of the biodiversity examined is represented by the balance of these indices. This concurs with the reports by Hooper et al. (2005), Petchey \& Gaston (2002) and Petchey et al. (2004) where they considered that biodiversity had a variety of "functional components". Hooper et al. (2005) continue to add that these could be properties such as: species composition, species richness, species evenness and species interactions. It is important to also consider that the usual measure of biodiversity, species richness, is considered by these authors to convey the least amount of information. The list of "properties" of biodiversity given by these authors matches very closely those derived by Feest (2006) independently.

\section{Materials and Methods}

The components of biodiversity quality Feest $(2006,2007)$ describes how well surveyed organism biodiversity data can be converted into the following indices:

1. Species richness: The number of species per unit area or per unit sample.

2. Biodiversity index: These are measures of evenness of different species or dominance by a single species. The normally used versions are: Shannon-Wiener, Simpson and Berger-Parker. These can be calculated by numbers of individuals or by biomass.

3. Population density: The number of individuals per species and per total sample or frequency of occurrence for those species without determinate form.

4. Biomass: Calculated from the measured individuals that have definitive form so for example the biomass of macrofungi is proportional to the cap area (Toth \& Feest 2007). For insects biomass is a function of body length or wing width (Brady \& Noske 2006).

5. Species Conservation Value Index (SCVI): This is an arbitrary value allocated to each species based on its conservation value. This value is normally a function of its commonness or rarity but it could be based on an intrinsic value according to human valuation or ecosystem functional importance. The coding is based on a skewed set of values to allow the rarer species to be registered by the calculations. Normally the SCVI is expressed as a mean and standard deviation; the latter of these highlights the presence of rare species. For the examples used in this paper the following scoring system was used: Abundant $=2$; Common $=3$; Frequent $=4$; Occasional $/$ Local $=5$; Rare $=10$; Really Rare $=20$; Red Data Book Species $=100$.

Indices (1)-(4) above are the ones that match those suggested by Hooper et al. (2005) and only the SCVI is a freshly created index. For butterflies a second version of this index was calculated which recorded the nitrophilic/nitrophobic tendencies of the species: the Species Nitrogen Value Index (SNVI).

For the calculation of these biodiversity indices the data was entered into a bespoke 


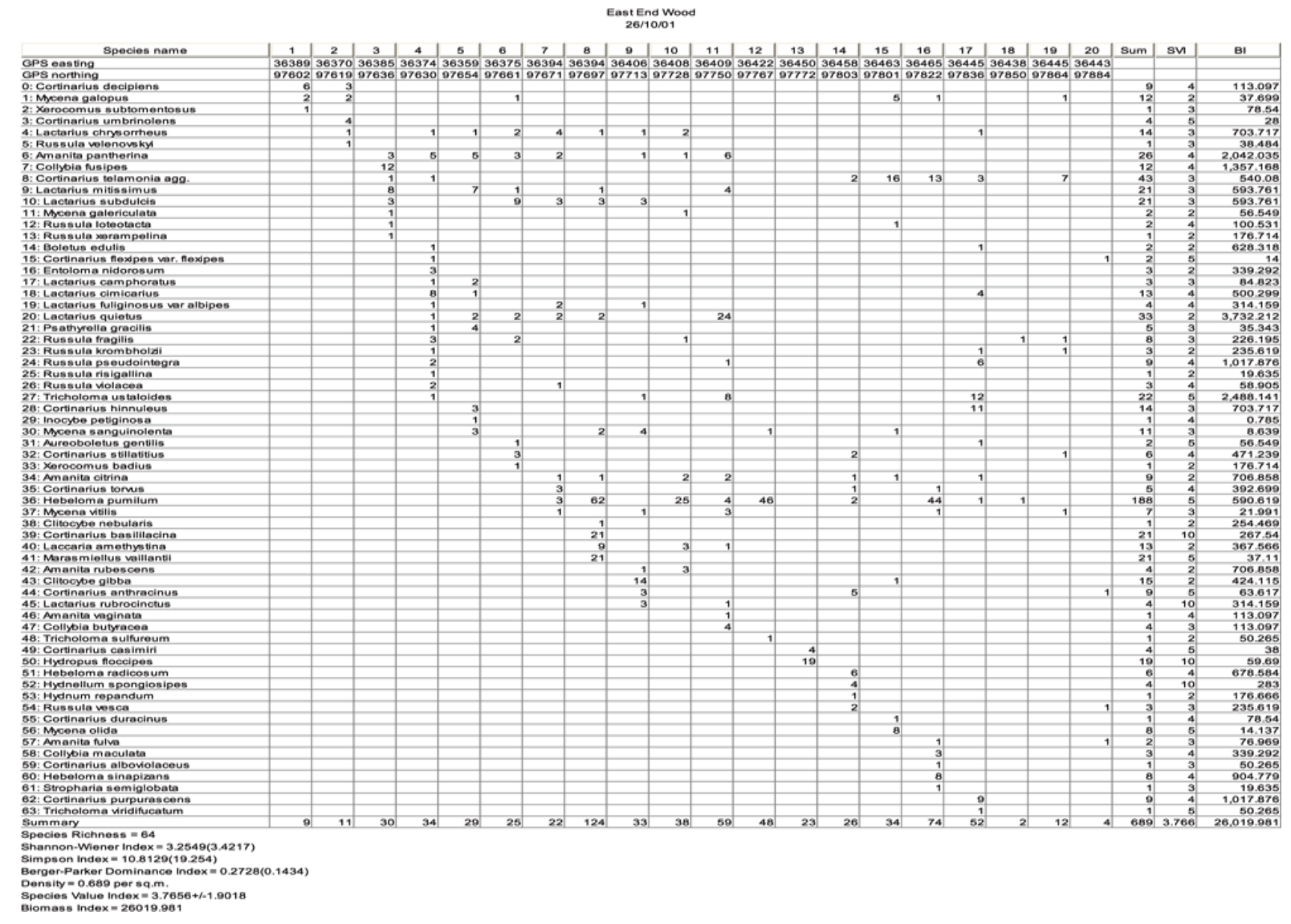

Fig. 1 - The biodiversity quality indices and species accumulation curve for the macrofungi of a woodland site in the UK. Specimen of the printout from the computer programme FuNGIB (see text for more details).

computer programme (FUNGIB) and specimen of the printout is shown in Fig. 1.

\section{Sampling}

Macrofungi were sampled following the scheme given by Feest (2006) where a transect route was followed and at each stop point all of the macrofungi in a $4 \mathrm{~m}$ radius circle $\left(50 \mathrm{~m}^{2}\right)$ were counted until 20 subsamples had been made. For the butterflies survey data for a 17 year period was supplied by Dr. Chris van Swaay from the Dutch Der Vlinderstichting butterfly recording scheme which follows a version of the Pollard and Yates transect sampling process.

\section{Research hypotheses}

Two hypotheses were tested

1. It is possible to create a series of biodiversity quality indices for macrofungi and that these can be compared between sites.

2. It is possible to convert butterfly survey data to biodiversity indices and these can be tested for environment effects.

In this latter hypothesis we have created a sub-hypothesis that butterfly biodiversity quality is affected by nitrogen deposition.

\section{Data}

Data for macrofungal biodiversity quality index calculation was compiled by one of the authors (AF) and Mr J. Smith on two sites in the West of England, UK. Butterfly data was supplied by Dr. Chris van Swaay from the Dutch Der Vlinderstichting butterfly monitoring programme and the nitrogen deposition data was supplied as Critical Load Exceedence (CLE) data (the amount by which

Tab. 1 - Biodiversity quality indices of two macrofungal woodland sites. See text for explanation.

\begin{tabular}{lcc}
\hline \multicolumn{1}{c}{ Parameter } & $\begin{array}{c}\text { East End } \\
\text { Wood } \\
\mathbf{2 9 / 1 0 / 0 1}\end{array}$ & $\begin{array}{c}\text { Weston } \\
\text { Big Wood } \\
\mathbf{2 4 / 0 9 / 0 0}\end{array}$ \\
\hline Species richness & 64 & 44 \\
Shannon-Wiener & 3.255 & 2.538 \\
& $(3.422)$ & $(2.4)$ \\
Simpson's & 10.813 & 7.419 \\
& $(19.254)$ & $(6.435)$ \\
Berger-Parker & 0.273 & 0.246 \\
& $(1.143)$ & $(0.301)$ \\
Fruit body density & 0.689 & 0.731 \\
(m ${ }^{-2}$ ) & & \\
Species value index & $3.766 \pm$ & $4.682 \pm$ \\
( \pm STD) & 1.901 & 3.785 \\
Cap area index & 26019 & 15285 \\
(Biomass) & & \\
\hline
\end{tabular}

nitrogen deposition exceeds the capacity of the habitat to absorb it without ecological effect) by Dr. Arjen van Hinsberg of the Netherlands Environmental Assessment Agency.

\section{Statistical methods}

The macrofungal mean data was tested for comparison of two sites by $t$-Tests and $\mathrm{F}$ Tests on the mean and standard deviations of the compiled indices and the effect of nitrogen deposition (CLE) effect on butterfly populations in Dutch woodland was tested by Principle Component Analysis (PCA) due to the need to view the combined interactive changes in the biodiversity. In PCA the results are presented as a number of eigenfactors for a series of artificial axes where the power of each index is shown in relation to the others.

\section{Results}

\section{Fungi}

Fig. 1 presents an ample of a site where macrofungi have been sampled and the indices calculated by FunGIB printed in the left hand corner. A useful adjunct of this type of data presentation is that it shows the species accumulation curve and the curve appears to be flattening off at sub-sample 17 indicating 
Tab. 2 - The $t$-Test and $\mathrm{F}$ test results comparing the two woodland sites in Tab. 1 for biodiversity quality differences.

\begin{tabular}{lcc}
\hline \multicolumn{1}{c}{ Parameter } & $\boldsymbol{t}$-Test & F Test \\
\hline Fruit body density & $\mathrm{p}=0.353$ & $\mathrm{p}=0.002$ \\
SCVI & $\mathrm{p}=0.135$ & $\mathrm{p}=0.001$ \\
Biomass & $\mathrm{p}=0.710$ & $\mathrm{p}=0.028$ \\
\hline
\end{tabular}

that the surveyed species richness of 64 is approximately that present on the whole site at the time of the survey.

Tab. 1 presents the calculated indices for the macrofungi of two sites. A review of the data shows that the two sites have similar indices but reference to Tab. 2 where the results of the $t$-Tests and F Tests are presented show that whilst the mean and total values do not differ significantly ( $t$-Test) the range of values (F Test) does differ for Fruit body density, SCVI and biomass showing that in particular the site with the rarest species has a significantly higher SCVI range of values despite there being fewer species present.

Tab. 3 - Principle component analysis of Woodland butterfly data from the Der Vlinderstichting survey over a 17 year period. SNVI = Species Nitrogen Value Index; SCVI $=$ Species Value Index; CLE $=$ Nitrogen Critical Load Exceedence. $\mathrm{PC} 1=66.6 \%$ of variation; $\mathrm{PC} 2=16.5 \%$ of variation and PC3 $=8.3 \%$ of variation. Figures labelled with $(*)$ in PC2 are for emphasis.

\begin{tabular}{lccc}
\hline \multicolumn{1}{c}{ Variable } & PC1 & PC2 & PC3 \\
\hline SNVI & 0.395 & 0.154 & -0.591 \\
Species richness & -0.451 & -0.013 & 0.002 \\
Simpson & -0.294 & $-0.497^{(*)}$ & -0.43 \\
SCVI & -0.417 & -0.017 & 0.467 \\
Population & -0.381 & $0.486^{(*)}$ & -0.279 \\
Biomass & -0.381 & $0.488^{(*)}$ & -0.274 \\
CLE & -0.299 & $-0.505^{(*)}$ & -0.307 \\
\hline
\end{tabular}

\section{Butterflies}

The PCA data presented in Tab. 3 shows that all indices are very similar in component 1 (representing $66.6 \%$ of variation) except for the SNVI. This would be interpreted as all indices declining except for the SNVI which is increasing and the butterflies species are becoming more nitrophilic. The second component ( $16.5 \%$ of variation) is far more informative showing width $(*)$ : a) that species richness and SCVI have low values and are not important in this component; $b$ ) population and biomass are similar (An expected outcome given that butterflies do not differ greatly in size) and c. that Simpson index and critical load exceedence (CLE) are similar and opposite to population/biomass which would be interpreted as with decreasing CLE populations of butterflies decline as the sites become less populated by nitrophilic species and the nitrophobic species increase (evenness declines). The third component accounts for only a small proportion of the variation $(0.083 / 1.0)$ and this will not be considered although in other datasets it may have greater relevance.

\section{Conclusions}

We have shown that further assessment (metadata analysis) of well surveyed data can yield more information and that this information can be assessed statistically for probability of importance. The first hypothesis is shown to be supported and that when such a difficult group of organisms as macrofungi are surveyed in a standardized way biodiversity quality indices can be created leaving analysis for difference between sites and over time. Since macrofungi either as decomposers and/or as mycorrhizae have a prominent place in forest/woodland ecosystems this will be of considerable utility in deciding on such things as the impact of global climate change or the effect of management activities.

The second hypothesis is supported by the calculation of indices (not presented) which have then been tested by PCA against a physical input: CLE. Is interesting to note that the CLE was declining rapidly throughout the period of surveyed data although it was still positive and therefore theoretically still having an effect. The principle component analysis has shown that if the usually measured element of biodiversity: species richness, had been used then no effect could have been detected that was not similar to all the other indices (in other words it might be more a result of interaction of factors that a direct effect). The second component in particular lends support to the arguments of Saint-Germain et al. (2007) for biomass to be taken much more seriously in biodiversity analysis.

In summary we conclude that adding further data treatment of biodiversity survey data by the creation of a range of biodiversity quality indices can provide far more information for the ecologist at no extra survey cost. Indeed the structured surveying advocated by Feest $(2006,2007)$ could be used to reduce field sampling effort without the loss of information. The use of biodiversity quality indices could be of considerable importance in setting baselines for judging progress towards the 2010 target of reducing the rate of loss of biodiversity by 2010 .

\section{Acknowledgements}

We thank Dr. Chris van Swaay and Der Vlinderstichting for supplying the data on Dutch butterflies; Dr. Arjen van Hinsberg for data on nitrogen critical load exceedence values for the Netherlands. We thank the European Environment Agency for the con- tract to $\mathrm{AF}$, Chris van Swaay and Arjen van Hinsberg (EEA/BSS/07/010) to assess the effect of nitrogen critical load exceedence. We thank Mr. J. Smith for the data and macrofungal identifications used in this paper.

\section{References}

Billeter R, Liira J, Bailey R, Arens P, Augenstein I, Aviorn S, Baudry J, Bakucel R, Burel F, Cerny M, De Blust G, De Cock R, Diekolter T, Durka W, Frenzel M, Hamersky R, Hendrickx F, Klotz S, Koolstra B, Lausch B, Le Coeur D, Maelfait JP, Opdam P, Roubalova M, Schermann A, Schmidt T, Schweiger O, Smulders MJM, Speelmans M, Simova P, Verboom J, van Wingerden WKRE, Zobel M (2008). Indicators for biodiversity in agricultural landscapes: a panEuropean study. Journal of Applied Ecology 45: 141-150. - doi: 10.1111/j.1365-2664.2007. 01393.x

Brady CJ, Noske RA (2006). Generalised regressions provide good estimates of insect and spider biomass in the monsoonal tropics of Australia. Australian Journal of Entomology 45:187-191 doi: $10.1111 / \mathrm{j} .1440-6055.2006 .00533 . \mathrm{x}$

Feest A (2006). Establishing baseline indices for the environmental quality of the biodiversity of restored habitats using a standardized sampling process. Restoration Ecology 14:112-122. - doi: 10.1111/j.1526-100X.2006.00112.x

Feest A (2007). Getting the best out of data. Developing best practice in surveying and reporting. Proceedings of the Institute of Ecology and Environmental Management, 18 April 2007, London, UK, pp. 51-58.

Hooper DU, Chapin FS, Ewell JJ, Hector A, Inchausti P, Lavoral S, Lawton JH, Lodge DM, Loreau M, Naeem S, Schmid B, Setala H, Symstad AJ, Vandermeer J, Wardle DA (2005). Effects of biodiversity on ecosystem functioning: a consensus of current knowledge. Ecological Monographs 75 (1): 3-35. - doi: 10.1890/04-0922 Maiorano L, Falcucci A, Garton EO, Boitani L (2007). Contribution of Natura 2000 Network to biodiversity conservation in Italy. Conservation Biology 32: 1433-1444. - doi: 10.1111/j.15231739.2007.00831.x

Petchey OL, Gaston K (2002). Functional diversity (FD), species richness and community composition. Ecology Letters 5: 402-411. - doi: 10.1046/j.1461-0248.2002.00339.x

Petchey OL, Hector A, Gaston K (2004). How do different measures of functional diversity perform. Ecology 85 (3): 847-857. - doi: 10.1890/ 03-0226

Saint-Germain M, Buddle CM, Larrivee M, Mercado A, Motchula T, Reichert E, Sackett TE, Sylvain Z, Webb A (2007). Should biomass be considered more frequently as a currency in terrestrial arthropod community analysis? Journal of Applied Ecology 44: 330-339. - doi: 10.1111/j.1365-2664.2006.01269.x

Toth BB, Feest A (2007). A simple method to assess macrofungal sporocarp biomass for investigating ecological change. Canadian Journal of Botany 85: 652-658. - doi: 10.1139/B07-068 